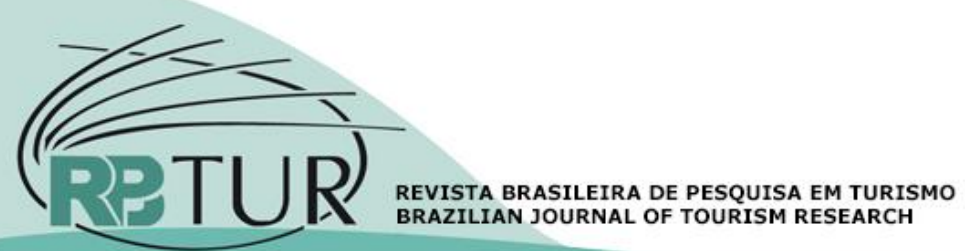

\title{
Artigos
}

\section{O Processo de Institucionalização das Estruturas Formais de Investigação em Turismo (EFIT) no Brasil}

\section{The Institutionalization Process of the Formal Structures of Tourism Research (FSTR) in Brazil}

\section{El Proceso de Institucionalización de las Estructuras Formales de Investigación en Turismo (EFIT) en Brasil}

\author{
Thiago Duarte Pimentel 1; Fabíola Cristina Costa de Carvalho 2; Mariana Pereira Chaves Pimentel ${ }^{3}$ \\ 1 Universidade Federal de Juiz de Fora (UFJF), Juiz de Fora, Minas Gerias, Brasil \\ 2Universidade de Guadalajara/Centro Universitario de la Costa, Guadalajara, Jalisco, México \\ 3Universidade Federal de Juiz de Fora (UFJF), Juiz de Fora, Minas Gerais, Brasil
}

Palavras-chave:

Estruturas Formais de Investigação em Turismo/EFIT;

Teoria Institucional;

Processo de Institucionalização; Instituição de Ensino Superior/IES: Brasil.

\section{Keywords:}

Formal Structures of Tourism Research/FSTR;

Institutional Theory;

Institucionalization Process;

Higher Education Institution/HEl; Brazil.
Resumo

Este artigo analisa o processo de institucionalização - habitualização, objetivação e sedimentação (Berger e Luckmann, 1966) - das Estruturas Formais de Investigação em Turismo/EFIT no Brasil, através da teoria institucional, em sua perspectiva histórica. Esta pesquisa, descritiva e explicativa, é do tipo censo. Empiricamente, recorreu-se a apreensão de dados secundários, de todos os 234 grupos de pesquisa formalmente registrados desde 1964 e ativos em 2016 no diretório de grupos do CNPq, eleitos como o tipo mais representativo de EFIT na pesquisa anterior (Pimentel, 2016a). Os dados foram tratados quantitativamente por meio do software SPSS e qualitativamente pela técnica de análise de conteúdo. Foram identificadas 3 etapas marcantes no processo de institucionalização das EFIT no Brasil: na primeira fase (1964-2001) de Habitualização, criaram-se cursos superiores para a formação em turismo, expandiu-se o tema "turismo" no ambiente acadêmico e observou-se sua inserção como linha de pesquisa. Na segunda fase, da Objetivação (2002-2009), o tema consolidou-se via criação de grupos específicos de pesquisa, em grande quantidade. Na terceira fase (2010-atual), sedimentam-se as EFIT, observa-se o contingente de egressos de graduações em turismo, com mestrado e doutorado, inseridos em IES como professorespesquisadores e começa a formar-se novas gerações de pesquisadores. Todavia, uma plena institucionalização requer a transmissão intergeracional de estruturas objetivas e referencias simbólicas de geração de conhecimento.

Abstract

This paper analyses the institutionalization process - habitualization, objectivation and sedimentation (Berger \& Luckmann, 1966)- of the Formal Structures of Tourism Research (FSTR) in Brazil, guided by the institutional theoretical lenses, in its sociological perspective. This is a descriptive and explanatory census research. Empirically, secondary data was collected from all 234 FSTR existing since 1964 and active in 2016 in the CNPq (Science and Technology Council) directory of research groups, elected as the most representative type of FSTR in the previous survey (Pimentel, 2016). The data was submitted to the quantitative 
Palavras clave:

Estructuras Formales de Investigación en Turismo/EFIT;

Teoría Institucional;

Proceso de Institucionalización; Institución de Enseñanza Superior/IES;

Brasil.

Revisado por pares.

Recebido em: 05/08/2018

Aprovado em: 06/02/2019 statistical method using the SPSS software and qualitatively by the contend analyses technique. It was identified 3 main periods regarding the FSTR institutionalization process in Brazil: the first one (1964-2001), the Habitualization, higher education courses were created for the training in tourism, the theme "tourism" was expanded in the academic environment and it was observed its insertion as a line of research. The second one, Objectivation (20022009), the theme was consolidated through the creation of specific groups of research, in a huge expansion. The third one (2010-nowdays), there is a sedimentation of the FSTR, the contingent of tourism graduation, with masters and doctorates, inserted in High Education Institutions as teacher-researchers, and new generations of researchers are beginning to form. However, the full institutionalization process requires the intergenerational transmission of the objective structures, as well as the symbolic references of knowledge generation.

\section{Resumen}

Ese artículo analiza el proceso de institucionalización - habitualización, objetivación y sedimentación (Berger y Luckmann, 1966) - de las Estructuras Formales de Investigación en Turismo/EFIT en Brasil, por medio de la teoría institucional, en su perspectiva sociológica. Esa investigación, descriptiva y explicativa, es del tipo censo. Por lo tanto, se recorrió a la aprehensión de datos secundarios, de todas las 234 EFITs, existentes entre 1964 y 2016 , empíricamente consideradas como grupos de investigaciones formalmente registradas y activas en el directorio de grupos en el CNPq (Pimentel, 2016). Los datos fueron tratados cuantitativamente con el apoyo del sof-tware SPSS y cualitativamente por la técnica de análisis del contenido. Fueron identificadas 3 etapas importantes en el proceso de institucionalización de las EFITs en Brasil; en la primera etapa (1964-2001) de Habitualización, se crearan cursos superiores para la formación vocacional en turismo, se expandió el tema "turismo" en el ambiente académico y se observó su inserción como línea de investigación. En la segunda etapa, de la Objetivación (2002-2009), el tema se consolidó vía creación de grupos específicos de investigación, en gran cantidad. En la tercera etapa (2010-actual), se sedimentó las EFITs, se observó el contingente de egresos de graduaciones en turismo, con maestría y doctorado, e insertos en IES como profesores-investigadores, empieza la formación de nuevas generaciones. Todavía, una plena institucionalización requiere la transmisión intergeneracional de estructuras objetivas y referencias simbólicas de generación de conocimiento.

Como citar: Pimentel, T. D.; Carvalho, F. C. C.; Pimentel, M. P. C. (2019) O Processo de Institucionalização das Estruturas Formais de Investigação em Turismo (EFIT) no Brasil. Revista Brasileira de Pesquisa em Turismo, São Paulo, 13 (3), p. 16 - 35, set./dez. http://dx.doi.org/10.7784/rbtur.v13i3.1493

\section{INTRODUÇÃO}

O objetivo deste artigo é analisar o processo de Institucionalização das Estruturas Formais de Investigação em Turismo (EFIT) no Brasil, aqui entendido como o surgimento, expansão, consolidação e sedimentação do campo de ensino e pesquisa do turismo.

Analisa-se a trajetória de propagação dos grupos especializados na pesquisa em turismo no Brasil, nos últimos 50 anos, buscando identificar particularmente as suas características estruturais, seguindo o modelo de análise organizacional (Musselin, 2005; Dimaggio \& Powell, 2005; Pimentel, Pereira \& Boas, 2011; Pimentel, 2014a), e as atividades que realizam, para extrair elementos explicativos sobre o atual estágio da pesquisa acadêmica em turismo no Brasil.

O fundamento primeiro desta proposta foi diferenciar a produção científica coletiva, estruturada, estabilizada e perene - assumindo como premissa a ideia de que este segundo tipo de produção científica, já representaria, em algum grau, um processo institucionalizado- daquela pesquisa que é realizada de forma individual, voluntária, espontânea, assistemática e inconstante ao longo do tempo (Pimentel, 2016a; Pimentel, Carvalho \& Bifano-Oliveira, 2017).

Deste modo, ancorados na perspectiva da sociologia do conhecimento (Merton, 1945; Gurvitch, 1964) busca-se precisamente responder à questão: pode o turismo ser considerado um campo de conhecimento institucionalizado no Brasil? Esse questionamento fundamenta-se no argumento de que as instituições de educação, devido à sua capacidade de atualização, de retroação e intervenção em outros sistemas, ocupam papel privilegiado nas sociedades contemporâneas, inserindo-se nesse contexto como estruturas altamente especializadas, cujos resultados afetam de forma contundente os demais sistemas sociais (Pimentel, Carvalho \& Pimentel, 2017). Deste modo, espera-se que o conhecimento não seja apenas produzido, mas também reproduzido no ambiente acadêmico, configurando assim um processo, por excelência, morfogênico e morfoestático (Buckley, 1971; Archer, 1998). 
Esta pesquisa, recorre ao arcabouço teórico da teoria institucional, em sua perspectiva histórica e sociológica, onde buscou-se identificar as etapas de institucionalização do turismo no contexto universitário brasileiro, assim como evidenciar o(s) modo(s) pelo(s) qual(is) tais formas modulam diferentes arranjos, no processo de emergência do subcampo acadêmico do turismo no Brasil (Pimentel, 2016a), por meio da elaboração de uma ordem social (Friedberg, 1996), que se materializa e estabiliza através da constituição de estruturas formais de pesquisa em turismo.

Especificamente, exploramos o conceito de dependência de trajetória (Mahnoey, 2000) da pesquisa em turismo em relação à constituição empírica das estruturas formais de pesquisa em turismo. Tal conceito, nos ajuda a compreender como as ações e estruturas precedentes condicionaram possibilidades de escolhas subsequentes e, deste modo, criam os resultados que vemos hoje. Por outro lado, defende-se que assumir consciência em relação a um estado de coisas, presente no contexto atual, nos permite efetuar alterações em determinada trajetória tendencial, alterando possibilidades futuras. No tocante às EFIT, no Brasil, tal conhecimento nos permite não só entendermos como chegamos até aqui, como também, eventualmente, traçar possibilidades de rotas alternativas, além de prognosticar determinadas situações futuras desejáveis.

Estudos na área do turismo com base nos pressupostos da teoria institucional ainda são recentes e incipientes (Song, Dwyer, Li \& Cao, 2012; Lavandoski, Albino Silva \& Vargas-Sánchez, 2014; Pimentel, 2014a, 2014b; Carvalho, 2015; Cintra, Amâncio-Vieira \& Costa, 2016; Falaster, Zanin \& Guerrazzi, 2017; Endres \& Matias, 2018), sendo ainda mais escassos quando se especifica o tipo de vertente da teoria institucional, por exemplo, o institucionalismo histórico (Endres \& Matias, 2018; Estol, Camilleri \& Font, 2018; Falaster, Zanin \& Guerrazzi, 2017; Carvalho, 2015) e, sobretudo, quando aplicado ao tema da pesquisa em turismo (Falaster, Zanin \& Guerrazzi, 2017; Pimentel, 2016b; Pimentel, Carvalho \& BifanoOliveira, 2017; Pimentel, Carvalho \& Pimentel, 2017; Pimentel, Carvalho \& Oliveira, 2018). Além disso, parte considerável desta já escassa literatura dedica-se a produzir estudos de revisão teórica, o que sugere o potencial ineditismo deste trabalho, cujo dialogo com a literatura supramencionada fornece evidências empíricas, de corte longitudinal.

O texto está organizado em cinco partes, além desta introdução. A seção 2 detalha o referencial teórico sobre teoria institucional e das organizações. A parte 3 discorre sobre o uso da teoria institucional nos estudos do turismo. A metodologia da pesquisa realizada é descrita na seção 4 . Na seção 5 se reúnem os resultados levantados sobre o processo de institucionalização das EFIT, seguida da discussão e análise dos resultados. A última parte (6) esboça as considerações finais do artigo.

\section{TEORIA INSTITUCIONAL E PROCESSOS DE INSTITUCIONALIZAÇÃO}

Para Berger e Luckmann (1966; 2004) a existência humana é resultado de formações socioculturais e psicológicas, que refletem uma ordem social, que antecede ao indivíduo, e ao mesmo tempo é influenciada e mantida pela própria ação do ser humano, em um processo continuo. Nesse sentido, é um produto exclusivo da atividade humana. Os autores utilizam a ideia de institucionalização para explicar as causas que levam a emergência ou a manutenção de uma ordem social, considerando que a atividade humana, que é apreendida e reproduzida do mesmo modo, com o mesmo esforço, ao longo do tempo, torna-se um padrão, revestido de um caráter significativo para o indivíduo.

Conforme Immergut (2007), as premissas da tradição institucional ou "velho" institucionalismo são anteriores àquelas das teorias sociais e políticas, e estão dedicadas a evidenciar como as instituições determinam o comportamento humano, por meio de suas preferências e decisões. Em meados do século XX os teóricos da ciência política concentravam suas explicações nos princípios Behavioristas e da Escolha Racional, tendo como base analítica as características sócio-psicológicas dos indivíduos (Peters, 1999; Immergut, 2007). No entanto, não se avaliavam as influências exógenas na determinação de decisões individuais (Peters, 1999).

Na década de 1980, um movimento de reafirmação das teorias institucionais nas ciências sociais passou a rejeitar a análise da conduta observável como um ponto básico de partida dos estudos políticos e sociais (Hall \& Taylor, 2003; Immergut, 2007). March e Olsen (1984) são assim considerados os precursores da 
revolução contrária ao individualismo metodológico, característico dos enfoques behavioristas (da antropologia/psicologia) e da Escolha Racional (de origem nas teorias político-econômicas) (Peters, 2000).

Nesse contexto, Hall e Taylor (2003) e Immergut (2007) separam a nova teoria institucional em três vertentes principais: Institucionalismo da Escolha Racional, Institucionalismo Sociológico e Institucionalismo Histórico.

O institucionalismo sociológico surgiu nos debates da década de 1970 como uma crítica a racionalidade da Carnegie School (Immergut, 2007). Segundo Peters (2000), as ideias centrais deste movimento são apresentadas por Zucker (1987), DiMaggio e Powell (1991) e Scott (1995). Argumentava-se, conforme Immergut (2007), que o tempo e a informação não eram suficientes para um indivíduo calcular as consequências de sua decisão. Neste sentido, o comportamento seria firmado sobre normas institucionais superiores à vontade de maximizar as preferências (March \& Olsen, 1984).

Esta perspectiva sustenta que procedimentos observados nas organizações modernas não foram adotados apenas pela eficiência, como sugere a noção de "racionalidade" (Hall \& Taylor, 2003). Nesse contexto, March \& Olsen $(2005$, p. 1) definem uma instituição como um conjunto de regras e práticas organizadas, que são relativamente duradouras, estão inseridas em "estruturas de significado", possuem recursos invariantes, mesmo com a rotatividade de indivíduos que a compõem, além de manterem-se "resilientes às preferências e expectativas idiossincráticas dos indivíduos" e ao ambiente externo cambiante.

Assim, deveria explicar-se as práticas burocráticas por fundamentos culturalistas ou subjetivos (Meyer \& Rowan, 1977; Meyer \& Scott, 1983; DiMaggio \& Powell, 1991), para esclarecer porque se incorporam procedimentos, ou símbolos, às práticas organizacionais. Portanto, uma dimensão cognitiva, a "cultura", tende a ser redefinida como sinônimo de "instituição" (Zucker, 1987; Powell \& DiMaggio, 1991; Meyer \& Scott, 1983).

Logo, as instituições condicionam o comportamento não apenas em ações concretas, mas também nos significados da vida social. Esse argumento é identificado no construtivismo social de Berger e Luckmann (1966; 2004), que consideram a determinação das instituições na identidade que os atores sociais têm de si mesmos.

O processo de institucionalização e seu resultado (as instituições), segundo Berger e Luckmann (1966; 2004), pode ser visto como fruto de processos de interação social e de interpretação da realidade, que ocorrem por meio de uma resposta inovadora a um determinado problema surgido em um contexto específico. A medida em que tal solução passa a ser usada de forma recorrente pelos membros do mesmo grupo, instaura-se um processo habitualização, e no momento que esta solução é hegemônica e oficialmente colocada como "a" forma de lidar com o problema, tal procedimento será considerado objetificado, como se fosse existente a priori. 0 ciclo se fecha quando ocorre a passagem desta forma de solução de um problema na realidade, da geração em curso para as gerações seguintes. 0 processo de deslocamento dessa referência para novos indivíduos que serão socializados nesta ordem vigente, sem o background do contexto originário do problema, nem a reflexão sobre outras possibilidades, levará ao estágio seguinte, a sedimentação, ocasião em que já é possível denominar-se como institucionalização, pois um mundo institucional "é experimentado como realidade objetiva" (Berger \& Luckmann, 2004, p. 86), percebido de forma independente dos indivíduos e de sua vontade. Na figura 1 representa-se o processo de institucionalização segundo as categorias de análise habitualização, objetivação e sedimentação, propostas por Berger e Luckmann (1966; 2004).

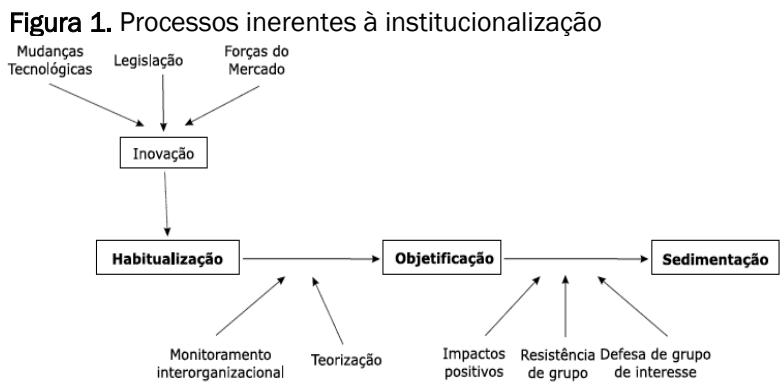

Fonte: Tolbert e Zucker (1998, p. 207); Carrieri, Saraiva e Pimentel (2008, p. 65) 
Peters (2000) considera que o institucionalismo histórico é uma versão mais elaborada do que as abordagens racionalista e sociológica, já que, em sua análise, além da atenção sobre as instituções formais tal abordagem expande-se para a observação do desenho das instituições e a forma como elas se manifestam, a partir da noção de que a configuração de grupos organizados e o poder de influência exercido por eles decorrem de conjunturas históricas (Hall \& Taylor, 2003). Portanto, a análise histórica é a base para a explicação de processos de institucionalização, pois ajuda a compreender como ocorreram mudanças contextuais que levaram a manutenção de ideias, significados, preferências e práticas sociais, enquanto em certos momentos se cria um ambiente favorável à mudança e a ressignificação de processos sociais.

Conforme tal perspectiva a instituição é definida como "os procedimentos, protocolos, normas e convenções oficiais e não oficiais" que estão relacionadas a uma estrutura organizacional (Hall \& Taylor, 2003, p. 196). Assim, fundamenta-se o argumento de que as instituições são componentes permanentes para o desenvolvimento histórico de um conjunto de "trajetórias" (Hall, 1986). A busca pela explicação dos caminhos que levaram a formação destas trajetórias é precisamente um dos principais interesses dos estudos desta vertente (Collier \& Collier, 1991), bem como a diferenciação de períodos de continuidade (ou estabilidade), dos eventos críticos que levam a mudança institucional (Gourevitch, 1986). O problema central consiste em explicar o que desencadeia estes momentos críticos (Skocpol, 1979; Gourevitch, 1986; Pierson, 2003).

Nesse sentido, a manutenção de sistemas sociais está associado à ideia de estabilidade e de prosperidade, ao passo que a possibilidade de mudança é observada por meio da identificação de divergências e demandas por esforços para que estes sistemas continuem operando a partir das mesmas normas e processos operacionais (Gourevitch, 1986). Assim, as instituições centrais para a operação de uma agenda de discussão devem reafirmar periodicamente seu empenho na atividade desenvolvida conforme as regras de um jogo estabelecido (Hall \& Soskice, 2001).

Cabe considerar que, as redes de relacionamento condicionam o desenho dos sistemas sociais, em função do cálculo dos custos de uma decisão para o próprio grupo e seu entorno, bem como dos benefícios buscados (Hall, 1986). Nesse contexto, é importante considerar que os constrangimentos que levam a formação de uma instituição são provenientes de estímulos do ambiente político, econômico e social dos atores que participam nos processos decisórios (Goodin, Rein \& Moran, 2008).

Além disso, fundamental na análise histórico-institucional, o conceito de dependência de trajetória apoia as explicações, de como e porque certas decisões são tomadas, ou ocorreram determinados movimentos, em detrimento de outras opções (Hall, 1986). Tal conceito é fundamentado na ideia de que as decisões do passado coagem os processos decisórios presentes e restringem as possibilidades dos atores buscarem novos direcionamentos, ainda que a decisão tomada não seja, a priori, a mais acertada ou eficiente naquele momento (Sckocpol, 1979; Hall, 1986). Nesse contexto, Thelen (2004) defende que existem eventos críticos, que levam as instituições a seguirem suas trajetórias, e que tais entidades estão em um constante processo de adaptação, em função do ambiente que as determina. Assim, enquanto diversos pequenos eventos ocorrem continuamente (Mahoney \& Schensul, 2006), o momento da mudança é o resultado de um processo histórico que se configura durante um longo período, o qual terá como resultado um evento específico que engatilha o início de um novo contexto (Pierson, 2003).

Tomando em conta esta separação, nesse trabalho nos enfocaremos preponderantemente - mas não exclusivamente ${ }^{1}$ - na perspectiva histórica do estudo das instituições, ou de forma mais específica, na senda sociológica histórica (Mahoney, 2000). A partir das contribuições da teórica institucional, precisamente os conceitos de habitualização, objetivação e sedimentação, bem como os conceitos de dependência de

\footnotetext{
${ }^{1}$ De fato, todas as perspectivas assumem pontos de partida e se revestem de modus operandi particulares ao priorizarem determinados elementos de análise na formação e manutenção de uma determinada ordem social, sendo, a rigor, talvez mais complementares do que efetivamente alternativas. Portanto, em certa medida, dialogaremos com a perspectiva sociológica de estudo das instituições, ao assumirmos determinadas premissas - por exemplo, de que as instituições são socialmente construídas, i.e., produto da ação humana (Berger e Luckmann, 1966; 2004). No entanto, nosso principal argumento, é de que há uma dependência de trajetória da pesquisa em turismo em relação à constituição empírica das estruturas formais de pesquisa em turismo, sendo, portanto, de base histórico-institucional
} 
trajetória e mudança institucional, buscar-se-á apresentar um exame sobre a formação do campo da pesquisa em turismo no Brasil.

\section{TEORIA INSTITUCIONAL E OS ESTUDOS EM TURISMO}

Gyr (2010) considera que a origem dos estudos do turismo foi no campo dos negócios e da economia, baseados em uma abordagem institucional; enquanto as análises baseadas nas ciências culturais e na pesquisa histórica apareceram em um momento posterior. No entanto, dada a polissemia do termo instituição - e sua frequente confusão com "organização", já que os estudos organizacionais não apresentam uma teoria ou perspectiva unificada, mas visões diversas conforme regiões geográficas e o compartilhamento de discursos (March, 2010) - é possível questionar sobre aquilo que se entendia por "abordagem institucional", ainda no início do século passado². Porém, apesar de sua raiz remota, a abordagem que tem sido mais comumente utilizada no turismo é a teoria de sistemas

Assim, apesar de sua reputação e popularidade nas ciências sociais, estudos em turismo que se beneficiam do framework da teoria institucional ainda são recentes e incipientes (Lavandoski, Albino Silva \& VargasSánchez, 2014), e, frequentemente, não especificam e aprofundam-se em uma de suas vertentes. Parte considerável desta já escassa literatura dedica-se a produzir estudos de revisão de literatura, ou, quando lidam com pesquisa empírica, o fazem a partir de estudos de caso (Pimentel, Pereira \& Boas, 2011).

No âmbito teórico Lavandoski, Albino Silva e Vargas-Sánchez (2014), apresentam as áreas, temas e objetos de pesquisa mais recorrentes em que a teoria institucional é utilizada no turismo (Figura 2). No plano internacional, segundo os autores, esta vertente tem sido mobilizada para analisar o turismo no tocante a estudos sobre: meio ambiente, empreendedorismo, inovação, tecnologia, responsabilidade social, arranjos institucionais, governança, políticas públicas e confiança política, sendo que frequentemente o foco recai sobre a articulação entre diversos stakeholders de um contexto específico. Adicionalmente, considera-se que tais estudos são sobremaneira subutilizados em face de sua consolidação como perspectiva teórica para explicar comportamentos organizacionais. Nesse sentido, Song et al. (2012), propõem a ampliação da adoção da perspectiva institucional em estudos sobre economia do turismo com o objetivo de estender as fronteiras de conhecimento existentes sobre o tema.

Quadro 1. Principais áreas de pesquisa de Teoria Institucional em Turismo

\begin{tabular}{|c|c|c|}
\hline Setor & Área de Pesquisa & Autores \\
\hline \multirow{9}{*}{ Turismo } & Meio ambiente & $\begin{array}{l}\text { Strambach \& Surmeier (2013); Riviera (2004); Shah (2011); Vargas-Sán- } \\
\text { chez \& Riquel-Ligero (2010; 2011; 2012); Riquel-Ligero (2010; 2011); Ri- } \\
\text { quel-Ligero \& Vargas-Sánchez (2012a; 2012b; 2013); Grimstad \& Burgess } \\
\text { (2012) }\end{array}$ \\
\hline & Empreendedorismo & McCarthy (2012); Roxas \& Chadee (2013) \\
\hline & Inovação & Ottenbacher \& Harrington (2009); Gyau \& Stringer (2011) \\
\hline & Tecnologias & Ali et al. (2013); Vatanasakdakul \& Aoun (2009) \\
\hline & Responsabilidade Social & Sánchez-Fernández (2012) \\
\hline & Arranjos Institucionais & $\begin{array}{l}\text { Forbord et al. (2012); karhunen (2008); Ingram (1998); Wilke \& Rodrigues } \\
(2013)\end{array}$ \\
\hline & $\begin{array}{l}\text { Estruturas de Gover- } \\
\text { nança }\end{array}$ & Lapeyre (2009); Lapeyre (2011a) \\
\hline & Políticas Públicas & Wang \& Ap (2013); Urbano et al. (2010) \\
\hline & Confiança Política & Nunkoo et al. (2012); Nunkoo \& Smith (2013) \\
\hline
\end{tabular}

Fonte: Traduzido de Lavandoski, Albino Silva e Vargas-Sánchez (2014, p. 35).

No âmbito dos estudos empíricos do turismo baseados na teoria institucional Aureli e Del Baldo (2019), procuram analisar o papel das organizações privadas, com foco na administração de Convention Bureaus, com particular atenção na diversidade entre os membros que formam a entidade e a necessidade de

\footnotetext{
2 De todo modo, o contexto a que se refere data do início do século XX, o que definitivamente implica, mesmo que se aceite a homologia conceitual, uma radical diferença entre a abordagem institucional dos anos (1920/1930), cunhada como velho institucionalismo, e sua evolução teórica conquistada na segunda metade do mesmo século (novo institucionalismo), isto, para não entrar em um debate mais profundo sobre os seus tipos e vertentes especificas.
} 
informação integrada sobre as ações no âmbito institucional. Assim, observam que o uso de metodologias baseadas na atenção às expectativas das partes interessadas restringe-se a temas vinculados na contribuição financeira, em detrimento de uma base moral que condicione as decisões destas entidades.

Também observando o caso do setor privado, Gomes, Vargas-Sánchez e Pessali (2014) analisam a interação do trade turístico, em Huelva (Espanha). Neste trabalho são enfatizados os conceitos de empreendedorismo, governança e políticas públicas. Os autores constatam que, apesar da consciência mútua entre setor público e empresários acerca de sua interdependência, há uma diferença em termos de comportamento onde, enquanto o setor público organiza, regula e tenta promover maior interação e sinergia entre os esforços dos atores; no setor empresarial parece predominar uma competição em pequena escala permeada por uma racionalidade oportunista. Ainda assim, há um grupo de empresários cujos objetivos convergem com o setor público, o que têm oportunizado a realização de políticas públicas mais sinérgicas e eficientes.

Ainda no contexto espanhol das empresas privadas, García-Cabrera e Durán-Herrera (2014), discutem como os efeitos de uma crise econômica estimulam as empresas turísticas a gerar inovação para manter-se competitivas. Assim, a promoção de mudanças em contextos institucionais por um lado, ou a busca por evitar mudanças consideradas prejudiciais a seus negócios, por outro lado são algumas das possíveis estratégias de ação identificadas nestes contextos relacionais. Como conclusão os autores destacam como se remodelou o ambiente compartilhado entre as organizações turísticas e o contexto político-institucional, por meio de um processo bi-direcional e co-evolutivo.

Na mesma linha, Le, Hollenhorst, Harris, McLaughlin e Shook (2006) analisam fatores que interferem na adoção ou rejeição de práticas amigáveis ao meio ambiente em organizações hoteleiras vietmamitas. Assim, observam os elementos condicionantes para a adoção de inovações nestas empresas. A partir de um estudo empírico, as características organizacionais, bem como a evidência de benefícios, são identificados como influentes nestes processos.

No Brasil também há indícios de poucos estudos em turismo amparados pela teoria institucional. Recentemente, Endres e Matias (2018) analisaram a trajetória dos principais atores que estão diretamente envolvidos com o desenvolvimento do turismo na Paraíba e em João Pessoa, entre 1970 e 2017. Amparados no arcabouço da teoria institucional, em sua vertente do institucionalismo histórico, observam as mudanças das instituições a partir de marcos, conjunturas críticas e legados deixados pela trajetória dos atores envolvidos no cenário turístico da região de estudo. Seus achados revelam que os órgãos públicos (em particular a PBTUR - Empresa Paraibana de Turismo) lideram a articulação de ações, apesar de sua frágil autonomia interna e da debilidade de recursos disponíveis; as políticas de criação de marcos regulatórios e instituições pouco avançaram no processo de desenvolvimento do turismo; e por último é preciso inserir a sociedade civil organizada nos processos decisórios.

Também observando a região nordeste do país, por meio de uma pesquisa exploratória e descritiva, Silva (2017) analisou como o poder público, em suas diversas esferas, estabeleceu historicamente estímulos à atividade turística, a partir de uma abordagem econômica e seus reflexos na institucionalização do turismo municipal no Brasil. Assim, aponta que o turismo se consolidou na agenda governamental como um vetor de desenvolvimento econômico. A metodologia do trabalho consistiu na seleção de 23 municípios turísticos, considerados prioritários para o governo do estado do Pará e atendidos por programas nacionais. Os resultados revelaram o perfil institucional e organizacional do turismo, na escala local, a partir de entrevistas e consultas documentais realizadas no período entre 2013 e 2016.

Outro estudo de caso realizado no cenário nacional é de Fazito, Scott e Russell (2016), que observam o processo de construção social do discurso sobre sustentabilidade na Serra do Espinhaço, eleita pela UNESCO uma reserva biológica. Assim, buscam as representações incorporadas neste território considerando suas origens e interesses diversos. Por fim, concluem pela formação de um discurso institucional pouco preciso, que colabora para que alguns grupos mantenham seu poder de decisão sobre o turismo.

Na região Sul do país, Araújo e Malheiros (2013) analisaram a evolução do desenvolvimento regional utilizando o modelo organizacional do Arranjo Produtivo Local (APL) entre firmas e outras instituições. A base teórica que sustenta o estudo é a teoria do desenvolvimento econômico com foco na figura do empresário 
inovador e no arranjo institucional do APL de Turismo Rota da Amizade, no Meio-Oeste do Estado de Santa Catarina.

Também no âmbito da interação dos atores locais do turismo, por meio de um estudo de caso qualitativo, Cintra, Amâncio-Vieira e Costa (2016) analisam a configuração do campo organizacional do turismo. Da teoria do stakeholder os autores utilizam as categorias analíticas "poder", "urgência" e "legitimidade" como suporte metodológico. Entretanto, ao ponderar sobre as brechas desta teoria para a compreensão do campo organizacional, devido à dificuldades (ou receio) de seus informantes no exercício de classificação das instituições conforme a categoria "poder", utilizam complementarmente o institucionalismo sociológico como base teórico-analítica.

Partindo da premissa de que as normas e regulamentos criados e consolidados em sociedade perfazem um conjunto de forças institucionais que pressionam as organizações a buscarem legitimidade em seu setor, Wilke e Rodrigues (2013) se propõem examinar o isomorfismo das organizações pertencentes ao setor de serviços, em particular da hotelaria, para compreender a sua legitimidade e os fatores que determinam sua ocorrência. Os autores concluem que as fontes de pressão institucional de legitimação das organizações hoteleiras originam-se, circunstancialmente, de uma ou da combinação, da utilização de mão de obra gerencial e técnica, do atendimento às exigências legais imperativas e facultativas e da imitação das organizações de sucesso.

Finalmente, no plano teórico, Carvalho (2015) observa a conjuntura de formação da agenda pública de turismo nacional, a partir de questões que desencadearam a elaboração das políticas de turismo, os atores participantes e os fatores condicionantes dessa dinâmica. Ainda, no plano teórico, por meio de uma revisão de literatura, Falaster, Zanin e Guerrazzi (2017) propõem a teoria institucional como marco para a análise da imagem de um destino e sua relação entre os turistas e a população local. Assim adotam os conceitos institucionais "legitimidade", "isomorfismo", "hibridização" e "categorização" como instrumento para a análise se estratégias para a construção à imagem dos destinos turísticos.

\section{METODOLOGIA}

A pesquisa é de tipo descritivo-explicativo (Gil, 1995/2008). Utilizou-se o método misto para a compilação e análise das informações textuais coletadas e sua codificação e tradução em informações quantitativas.

Em específico, dada a dificuldade de tratar de toda a diversidade de estruturas formais de pesquisa em turismo (EFIT) em uma mesma pesquisa, optou-se por tomar empírica e heuristicamente como objeto de pesquisa os "grupos de pesquisa" formais existentes no país, como um indicado do tipo proxy, capaz de, em boa medida, representar, em algum grau, a institucionalização da produção científica coletiva, estruturada, estabilizada e perene das EFIT do país. Tais grupos foram identificados através do "Diretório de Grupos de Pesquisa" do Conselho Nacional de Desenvolvimento Científico e Tecnológico (CNPq).

Este procedimento foi adotado com base na pesquisa exploratória realizada anteriormente por Pimentel (2016a), que identificou que de 57 estruturas formais de pesquisa vinculadas a instituições de educação superior com oferta educacional em turismo, apenas 1 (o Centro de Excelência em Turismo - CET, vinculado a Universidade de Brasília) tinha uma classificação diferente da denominação "grupo de pesquisa". Portanto, devido a representatividade deste tipo de estrutura no país, optou-se pelo enfoque nas EFIT vinculadas a plataforma Diretório de Grupos de Pesquisa ${ }^{3}$ do Conselho Nacional de Desenvolvimento Científico e Tecnológico (CNPq). Assim, a coleta de dados foi primordialmente secundária e realizada em duas etapas como descrito na tabela 1.

Tabela 1. Descrição do procedimento de coleta dos dados

\begin{tabular}{|c|c|c|c|c|c|}
\hline $\begin{array}{l}\text { Coleta de } \\
\text { dados }\end{array}$ & $\begin{array}{l}\text { Dia da } \\
\text { coleta }\end{array}$ & Termos de busca e filtros & $\begin{array}{l}\text { Total de grupos } \\
\text { identificados }\end{array}$ & $\begin{array}{l}\text { Total de CVs } \\
\text { identificados } \\
1,2\end{array}$ & $\begin{array}{l}\text { Início e fim da } \\
\text { coleta de CVs }\end{array}$ \\
\hline $1^{\mathrm{a}}$ fase & $\begin{array}{l}24 \text { de } \\
\text { janeiro }\end{array}$ & "turismo" & 163 & 238 & $\begin{array}{l}30 \text { de janeiro a } \\
10 \text { de fevereiro } \\
2017\end{array}$ \\
\hline
\end{tabular}

${ }^{3}$ Recuperado de http://dgp.cnpq.br/dgp/faces/consulta/consulta_parametrizada.jsf 


\begin{tabular}{|c|c|c|c|c|c|}
\hline & $\begin{array}{l}\text { de } \\
2017\end{array}$ & $\begin{array}{l}\text { Área de Conhecimento: Ciên- } \\
\text { cias Sociais Aplicadas; Área: tu- } \\
\text { rismo }\end{array}$ & & & \\
\hline $2^{a}$ fase & $\begin{array}{l}13 \text { de } \\
\text { março } \\
\text { de } \\
2017\end{array}$ & $\begin{array}{l}\text { "turismo", "hospitalidade”, } \\
\text { “meio ambiente", "geografia”, } \\
\text { "gastronomia”, “administra- } \\
\text { ção", “lazer" } \\
\text { Não aplicou-se outros tipos de } \\
\text { filtro nesse momento. }\end{array}$ & 312 & 110 & $\begin{array}{l}1 \text { de abril a } 25 \\
\text { de maio de } \\
2017\end{array}$ \\
\hline
\end{tabular}

Foram identificados inicialmente 475 grupos, sendo que 241 (50,73\% do total da amostra) eram estruturas multidisciplinares, ou que tem origem em outras áreas do conhecimento com pelo menos uma linha de pesquisa em turismo, enquanto 235 (49,47\%) eram especializados no tema do turismo. Vale esclarecer que a classificação "especializado no tema do turismo" seguiu dois critérios: (1) que os termos relacionados a turismo estivessem explícitos no nome do grupo; e/ou (2) que todas as linhas de pesquisa do grupo sejam relacionadas aos temas do turismo.

Estabeleceu-se como critério para a seleção dos grupos componentes da amostra analisada aqueles que fossem especializados em turismo e tivessem sido criados até 31 de dezembro de 2016, o que resultou em um total de 234 grupos. Para identificar e analisar a produção dos grupos, além dos dados proporcionados na plataforma do diretório do CNPQ, foi selecionada a informação sobre pesquisa, no currículo lattes dos coordenadores dos grupos de pesquisa.

Especificamente, a Análise de Conteúdo (AC) (Bardin, 1977) foi utilizada como uma técnica para o tratamento dos dados, por meio da categorização, codificação e conversão de dados qualitativos informações textuais disponíveis em sítios eletrônicos - em dados numéricos passíveis de serem contabilizados, os quais, por sua vez, foram analisados por meio do processamento estatístico descritivo no software SPSS.

Cumpre mencionar que a busca de um método, sistemático e seguro, para análise de informações textuais remonta à antiguidade e constitui-se em campo próprio da filosofia: a Hermêutica (Gadamer, 1999). No campo científico, é no início do século XX, nos EUA, com Lasswell, (1927), que a AC foi proto-analiticamente utilizada (Campos, 2004; Silva \& Fossá, 2015), sendo ampliada por Berelson e Lazarsfeld (1948), os quais, segundo Campos (2004), são os verdadeiros criadores da AC. É somente em 1977 que, na França, Laurence Bardin, trará à lume a sua sistematização da AC, versão que, todavia, tornou-se rápida e mundialmente difundida (Silva \& Fossá, 2015). Convém, no entanto, discernir que, além das épocas, dos contextos regionais (ou nacionais), e dos autores implicados, a análise de conteúdo também possui vertentes diferentes acorde sua influência epistemológica seja mais positivista, quantitativa, dedutiva-verificatória, seja mais interpretativa, qualitativa, indutiva-construtiva.

Como pondera Moraes (1999, p. 3):

\begin{abstract}
"Dependendo da abordagem de pesquisa utilizada a definição dos objetivos pode assumir dois rumos diferentes. Numa abordagem quantitativa, dedutiva, de verificação de hipóteses, os objetivos são definidos de antemão de modo bastante preciso. Constituem parte essencial do planejamento inicial que precede e orienta as fases posteriores da pesquisa, especialmente a definição dos dados e os procedimentos específicos de análise. Numa abordagem qualitativa, construtiva ou heurística, esta construção, ao menos em parte, pode ocorrer ao longo do processo. Nesta abordagem, assim como as categorias poderão ir emergindo ao longo do estudo, também a orientação mais específica do trabalho, os objetivos no seu sentido mais preciso, poderão ir se delineando à medida que a investigação avança. [...]".
\end{abstract}

Segundo Campos (2004), enquanto a lógica operativa da primeira se dá por frequenciamento ou quasiquantitativa (i.e. por meio da repartição de conteúdos comuns), a segunda forma opera por relevância implícita das unidades de análise. Mais recentemente, em debates contemporâneos, tem se visto o uso 
deste método [(ou técnica, dependendo de seu papel na pesquisa, se como método único ou central ou se como comento de uma bateria de técnicas, (Triviños, 1987)] em outras tradições epistêmicas marxistas (críticas) e construtivistas (Mozzato \& Grzybovski, 2011). No presente artigo, utilizamos a AC de forma complementar, apenas como técnica, em sua versão original, da primeira fase, positivista, quantitativa, dedutiva-verificatória, sendo esta portanto, coerente com os procedimentos quantitativos de pesquisa ora apresentados.

Deste modo, no quadro 2 são apresentadas as categorias analíticas e sua definição operacional referentes a caracterização dos grupos de pesquisa.

Quadro 2. Síntese do instrumento para a coleta dos dados dos grupos de pesquisa

\begin{tabular}{|c|c|c|}
\hline $\begin{array}{l}\text { Categoria teó- } \\
\text { rica }\end{array}$ & Categoria analítica & Definição operacional \\
\hline \multirow{9}{*}{ EFIT } & IES vinculada & pública ou privada \\
\hline & Distribuição no território ${ }^{1}$ & Estado (ente federativo) e localização geográfica no território nacional \\
\hline & Antiguidade & Ano de criação da EFIT \\
\hline & & $\begin{array}{l}\text { (1) Agenciamento, (2) Ciências da saúde, (3) Ciências Humanas, (4) Ciên- } \\
\text { cias Sociais, (5) Comunicação e marketing, (6) Desenvolvimento, susten- } \\
\text { tabilidade meio ambiente (7) Economia \& Gestão (8) Estado e Gestão }\end{array}$ \\
\hline & $\begin{array}{l}\text { Áreas Temáticas de Pes- } \\
\text { quisa }{ }^{2}\end{array}$ & $\begin{array}{l}\text { Pública (Public Affairs), (9) Eventos, (10) Gastronomia, (11) Geografia, Or- } \\
\text { denamento e Planejamento do Território, (12) Guia, (13) Hospitalidade, } \\
\text { (14) Lazer, (15) Patrimônio, (16) Transporte Turístico, (17) Turismo inter- } \\
\text { nacional, (18) Outros temas }\end{array}$ \\
\hline & $\begin{array}{l}\text { Grande área do conheci- } \\
\text { mento }^{3}\end{array}$ & $\begin{array}{l}\text { (1) ciências exatas e da terra, (2) ciências biológicas, (3) engenharias, (4) } \\
\text { ciências agrárias, (5) ciências sociais aplicadas, (6) ciências humanas, (7) } \\
\text { linguística, letras e artes, (8) outros }\end{array}$ \\
\hline & Recursos humanos & Pesquisador, estudante, técnico, colaborador internacional \\
\hline & Situação do participante & Membro atualmente ou egresso \\
\hline & Formação dos participante & Última formação do membro \\
\hline
\end{tabular}

Notas:

${ }^{1}$ Conforme a divisão do IBGE (Instituto Brasileiro de Geografia e Estatística) estabelecida desde 1941: Norte, Sul, Leste, Oeste, CentroOeste. O Distrito Federal foi considerado uma região separada do Centro-Oeste por sua importância como centro político do país

2 As áreas temáticas foram baseadas na classificação do protocolo de pesquisa proposto por Pimentel e Paula (2014).

3 Definidas conforme a classificação estabelecida pelo Conselho Nacional de Desenvolvimento Científico e Tecnológico (CNPq). Consultar: “Tabela de áreas do conhecimento”. Disponível em http://www.cnpq.br/documents/10157/186158/TabeladeAreasdoConhecimento.pdf. Acesso em 24 de setembro de 2017.

Fonte: adaptado de Pimentel e Paula (2014).

Finalmente, ressalta-se que por tratar de uma pesquisa ex post facto, de corte longitudinal, não existe a possibilidade de extrair informações de eventos passados que deixaram de existir, a não ser que tivessem deixado registros formalizados, por exemplo, por meio de alguma pesquisa anterior, o que, todavia, não se verifica no caso em tela. Portanto, esta pesquisa tratou de analisar a população "sobrevivente" EFIT (aqui tomados analiticamente pelos grupos de pesquisa formalmente registrados no CNPq). Por suposto, tal fato implica como limitante a possibilidade lógica de não ser captada por esta análise alguma EFIT que existiu no passado e não existe mais. No entanto, dada a extensão do estudo, de todos os casos da população (censo), a cobertura temporal de mais de meio século (cerca de 60 anos) e o padrão de configuração institucional dos grupos, cuja emergência - em maior expressão quantitativa - só ocorre após os anos 2000 (ou seja, há menos de 20 anos); ponderamos que ainda que existam casos não contemplados pela pesquisa, eles tenderão a ser mínimos (talvez da ordem de 5\% ou menos), o que não invalida o esforço representado pelo estudo. Deste modo, tais detalhamentos são algumas das possibilidades para a continuação desta agenda de estudos sobre a história de educação e pesquisa em turismo no Brasil, bem como os eventos e demais condicionantes que resultaram na formação das estruturas atualmente existentes neste campo, que poderão ser retomadas por estes ou outros autores dedicados ao tema. 


\section{ANÁLISE DOS RESULTADOS E DISCUSSÃO}

\subsection{Características gerais da inserção da pesquisa em turismo no ambiente universitário no Brasil}

Em uma pesquisa anterior Pimentel (2016a) observou que no Brasil um conjunto de 379 IES ofertam cursos de formação em turismo, sendo que 586 (73,52\%) tem regime jurídico privado, enquanto 211 (26,47\%) são instituições públicas. A estas IES estão vinculadas os 234 grupos de pesquisa, os quais compõem a amostra analisada. Especificamente, 202 (86,3\%) das EFIT estão conectadas a uma instituição pública, enquanto 32 $(13,7 \%)$ estruturas tem ligação com uma IES de origem privada (figura 6).

Figura 2. Regime Jurídico das Instituições de Educação Superior de origem das EFIT

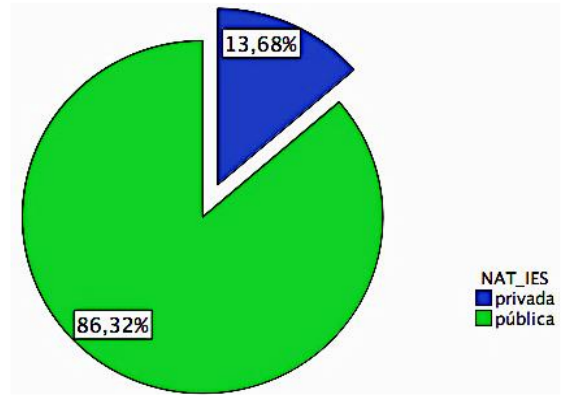

$\mathrm{N}=234$

Fonte: elaborado a partir dos dados da pesquisa.

\subsection{Marco de criação e expansão das EFIT}

Quanto a criação e expansão dos grupos de pesquisa em âmbito nacional foi observado que, até a década de 2000 o turismo predominava como uma linha de pesquisa nos grupos existentes. Especificamente, o primeiro grupo de pesquisa especializado no tema do turismo no Brasil foi registrado em 1993, o segundo em 1995 e o terceiro em 1997.

A partir de 2000 começa uma expansão destas entidades, de modo que a partir de 2006 houve a propagação contínua de grupos de pesquisa especializados no tema do turismo. Nos seguintes 5 anos, 83 grupos são formados. Nos primeiros seis anos da década de 2010, outros 122 grupos surgiram.

$\mathrm{Na}$ figura 3 é representada a expansão temporal da institucionalização da investigação científica em turismo no país, através de estruturas formais de pesquisa. Assim são diferenciados dois tipos de grupos, os que possuem linha de pesquisa em turismo (LT), cuja primeira evidencia data de 1964; a partir da aparição dos grupos específicos em turismo (TT) as estruturas LT diminuem sua representatividade, ainda que sejam observados até a data da coleta dos dados.

Figura 3. Expansão temporal dos grupos com linha de pesquisa em turismo (LT) e grupos especializados em turismo (TT) (N=234)

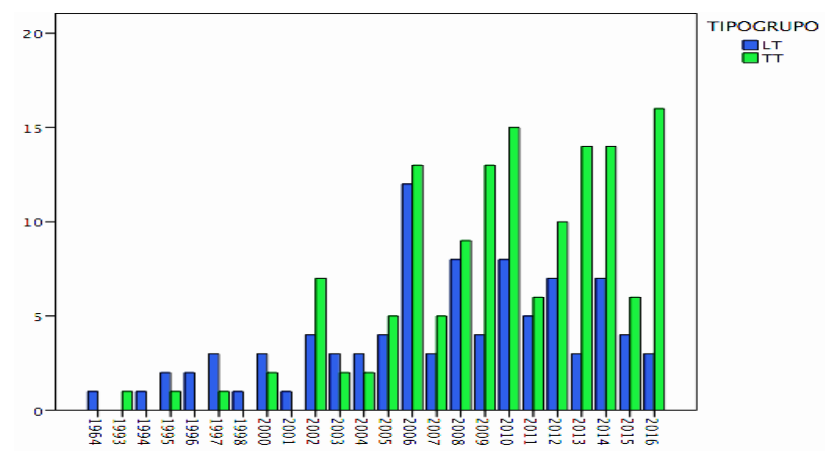

Fonte: elaborado a partir dos dados da pesquisa. 
Com relação a disposição espacial no território nacional, associado com a data de criação, se observou que a partir de 2006 é relativamente permanente o surgimento de EFITs em todas as regiões do país, todavia no sudeste e nordeste se observa uma multiplicidade de grupos predominante, em relação às demais regiões, enquanto que em todas as regiões há períodos de diminuição e aumentos da ocorrência dos grupos criados (Tabela 2).

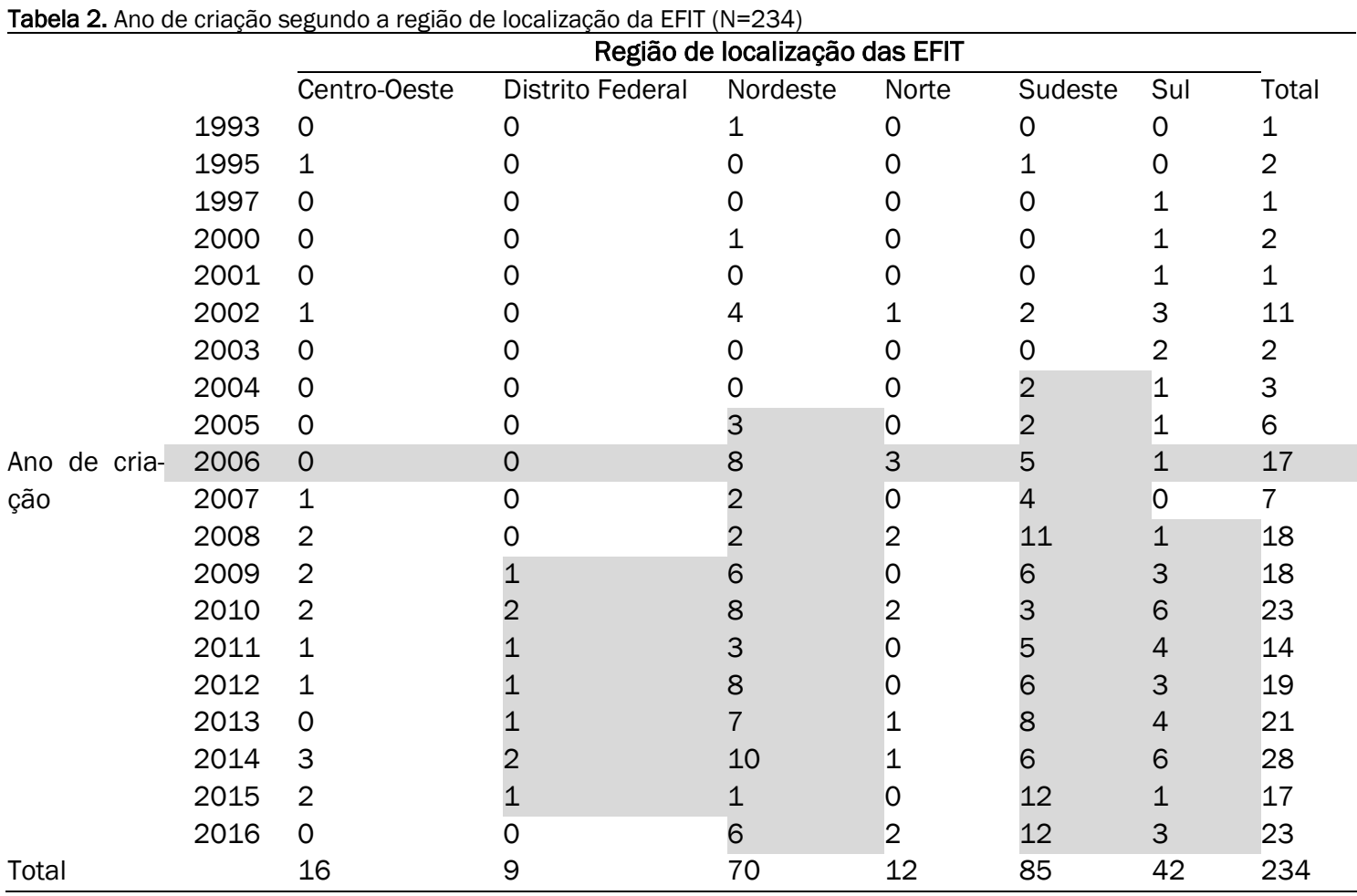

Fonte: elaborado a partir dos dados da pesquisa.

Outro indicador geral de diferenciação do sistema formal de investigação se refere a relação entre a distribuição das áreas temáticas das EFIT segundo as divisões por regiões do território nacional. Neste sentido nas regiões Sudeste e Nordeste há mais diversidade de temas estudados. Especificamente, no Sudeste de um total de 25 áreas temáticas identificadas, das quais em conjunto são observadas em 84 EFIT; as áreas de ciências sociais e planejamento turístico são as mais frequentes, com 13 e 12 observações, respectivamente (Tabela 3 ).

Tabela 3. Áreas temáticas das EFIT da região Sudeste Total de áreas temáticas da região Sudeste: 84

\begin{tabular}{lc} 
Áreas temáticas & Total por cada tema \\
Agronomia, Arquitetura, Transportes, Turismo & 2 \\
Eventos, Ciências da Saúde, Comunicação \& Marketing, Educação, Engenharia, Gastronomia, His- & 1 \\
toria, Psicologia, Turismo Internacional, Turismo Rural, Agenciamento & 3 \\
Ciências humanas, Patrimônio & 13 \\
Ciências Sociais & 7 \\
Economia \& Gestão & 4 \\
Lazer, Esportes & \\
Geografia, Meio ambiente & 5 \\
Hospitalidade & \\
Planejamento turístico & 9 \\
\hline
\end{tabular}

Fonte: elaborado a partir dos dados da pesquisa.

A região nordeste é a segunda com mais observações distribuídas, de modo que se identificaram 21 áreas temáticas, as quais se distribuem por 70 EFIT; o tema do planejamento turístico também é o mais frequente (Tabela 4). 
Tabela 4. Áreas temáticas das EFIT da região Nordeste Total de áreas temáticas da região Nordeste: 70

\begin{tabular}{ll}
\hline Áreas temáticas & Total por cada tema \\
$\begin{array}{l}\text { Agronomia, Alimentos, Ciências da Saúde, Esportes, Psicologia, Turismo, Turismo Internacional, Tu- } \\
\text { rismo Rural, Agenciamento }\end{array}$ & 2 \\
Ciências Humanas, Educação, Patrimônio, Historia & 7 \\
Ciências Sociais, Hospitalidade & 17 \\
Planejamento Turístico & 3 \\
Comunicação \& marketing & 4 \\
Economia \& Gestión & 5 \\
Gastronomia, Meio Ambiente & 6 \\
Geografia & 6
\end{tabular}

Fonte: elaborado a partir dos dados da pesquisa.

Por outro lado, na região Sul se observa uma frequência intermediaria, ou seja 42 EFIT observadas no total, nas quais se identificaram 16 áreas temáticas, em que planejamento turístico se mantem como mais frequente. Ainda as regiões Centro-Oeste (16), Norte (12) e o Distrito Federal (9) apresentam poucas EFIT, mais ainda nas duas primeiras a temática de planejamento continua predominante (Tabela 5).

Tabela 5. Áreas temáticas das EFIT do Centro-Oeste, Distrito Federal, Norte e Sul

\begin{tabular}{|c|c|c|}
\hline \multicolumn{2}{|c|}{$\begin{array}{l}\text { Total de temas por Áreas temáticas } \\
\text { Região }\end{array}$} & $\begin{array}{l}\text { Total por } \\
\text { cada tema }\end{array}$ \\
\hline \multicolumn{2}{|r|}{ Antropologia, Economia \& Gestão } & 1 \\
\hline \multicolumn{2}{|c|}{ Região Centro-Oeste: Gastronomia, Geografia } & 3 \\
\hline \multirow[t]{2}{*}{16} & Meio ambiente, patrimônio & 2 \\
\hline & Planejamento turístico & 4 \\
\hline \multirow[t]{2}{*}{ Distrito Federal: 9} & $\begin{array}{l}\text { Agronomia, Antropologia, Ciências humanas, Gastronomia, Hospitalidade, Meio } \\
\text { Ambiente, Patrimônio, Planejamento turístico, Transportes }\end{array}$ & 1 \\
\hline & Ciências humanas, Lazer, Geografia, Antropologia & 1 \\
\hline \multirow[t]{3}{*}{ Região Norte: 12} & Economia \& Gestão & 2 \\
\hline & Patrimônio, Planejamento turístico & 3 \\
\hline & $\begin{array}{l}\text { Alimentos, Antropologia, Ciências da Saúde, Ciências sociais, Comunicação \& Mar- } \\
\text { keting, Educação, Enoturismo, Lazer, História, Patrimônio }\end{array}$ & 1 \\
\hline \multirow{4}{*}{ Região Sul: 42} & Economia \& Gestão & 8 \\
\hline & Gastronomia, Hospitalidade & 4 \\
\hline & Geografia, Meio ambiente & 3 \\
\hline & Planejamento turístico & 10 \\
\hline
\end{tabular}

Fonte: elaborado a partir dos dados da pesquisa.

\subsection{Composição das estruturas de pesquisa segundo seus membros}

0 conjunto de indivíduos vinculados às estruturas analisadas está composto por 2.324 pesquisadores brasileiros, 27 pesquisadores que são colaboradores de nacionalidade estrangeira, 2.294 estudantes e 65 técnicos (Tabela 6). Neste agregado 3.463 estavam com seu status ativo nas EFIT, enquanto 1.252 eram egressos.

Tabela 6. Posição no grupo segundo o status de atividade $(\mathrm{N}=4.715)$

\begin{tabular}{lllll}
\hline & & Status & & Total \\
\cline { 3 - 5 } Posição & Ativo & Egresso & \\
& Colaborador estrangeiro & 27 & 0 & 27 \\
& Estudante & 1.466 & 828 & 2.294 \\
& Pesquisador & 1.905 & 424 & 2.329 \\
Total & Técnico & 65 & 0 & 65 \\
\hline & & 3.463 & 1.252 & $4.715^{*}$ \\
\hline
\end{tabular}

Nota: *Este representa o somatório por quantidade de membros de cada grupo de pesquisa analisado. Entretanto, é assumido que há indivíduos participantes em mais de um grupo, e, portanto, formam contados mais de uma vez.

Fonte: elaborado a partir dos dados da pesquisa. 
Em relação a esse indicador, destaca-se que os pesquisadores têm uma função essencial nos grupos, pois são eles que desenvolvem as principais atividades da EFIT. Os colaboradores estrangeiros representam a inserção destes sistemas no ambiente acadêmico internacional do turismo, o que impacta, por exemplo, na introdução de novos tópicos de pesquisa ou diferentes comportamentos do contexto nacional, devido à possibilidade de interação e aprendizagem.

Nota-se que, entre os 27 estrangeiros colaboradores identificados 4 representam casos duplicados, isto é, são indivíduos que participam de mais de uma EFIT. Considerando, pois 23 indivíduos identificados como colaboradores ligados a uma EFIT, predomina os vínculos de nacionalidade portuguesa (13 pesquisadores), enquanto México (4) e Espanha (3), são o segundo e terceiro casos mais frequentes. Argentina, Estados Unidos e Itália completam os países de origem dos colaboradores estrangeiros.

Nesse sentido, a capacidade de atração das EFIT brasileiras parece estar restringida pela fronteira linguística, uma vez que 56,52\% das observações são relacionadas com indivíduos que também são nativos do idioma Português. Ainda assim, México, Espanha e Argentina, que são países de idioma espanhol, representam o segundo grupo de países onde se observam ligações, enquanto os Estados Unidos e a a Itália, possuem menor ocorrência, apenas 2 casos.

Ainda se destaca que a presença dos alunos nos grupos é importante para a formação de novas gerações de pesquisadores e, claro, a renovação das estruturas. Por fim, os técnicos têm um papel relevante, pois, em geral, no Brasil, esses indivíduos estão mais ativamente envolvidos em outros setores, como os gestores públicos (técnicos da administração pública) ou o mercado (consultorias).

Buscou-se também caracterizar estes componentes das EFIT segundo seu último nível de formação. Para esta análise apenas o grupo dos pesquisadores, técnicos e colaboradores estrangeiros foram observados. Assim destaca-se na tabela 7 o nível de doutorado como destaque entre os pesquisadores, ainda que represente apenas metade destas observações, o que reforça a ideia de “juventude do campo", em relação ao grau de especialização de seus indivíduos. Em seguida, o nível de mestrado é também significativo, compondo $36,78 \%$ dos casos.

Por outro lado, também chama a atenção o fato de 4,01\% dos pesquisadores ter apenas o nível de graduação concluído e 0,83\% o nível técnico, enquanto as especializações/MBA representam 7,34\% dessas observações.

\begin{tabular}{|c|c|c|c|c|}
\hline $\begin{array}{l}\text { Última formação concluíd } \\
\text { componentes das EFIT }\end{array}$ & $\begin{array}{c}\text { a por gruposColaborador } \\
\text { geiro }\end{array}$ & estran- ${ }_{\text {Pesquisador }}$ & Técnico & Total \\
\hline Doutorado & 20 & 979 & 1 & 1000 \\
\hline Técnico & 0 & 16 & 3 & 19 \\
\hline Especialização/MBA & 0 & 141 & 22 & 163 \\
\hline Graduação & 1 & 77 & 13 & 91 \\
\hline Mestrado & 5 & 706 & 28 & 739 \\
\hline Total & 26 & 1919 & 67 & 2012 \\
\hline
\end{tabular}

Nota: Foram considerados válidos 2012 casos que podem ser relacionados ao mesmo indivíduo mais de uma vez. Fonte: elaborado a partir dos dados da pesquisa.

Em geral, prevalece as formações não-específicas em turismo em todos os níveis - técnicos, licenciatura, especialização, mestrado, doutorado e pós-doutorado. De um total de 1.274 observações, no nível de doutorado unicamente, $7,77 \%$ deste total representa uma formação específica em turismo. Por outro lado, no nível de graduação as formações específicas em turismo representam $28,89 \%$ das observações, o que indica maior oferta acadêmica especializada neste nível (Tabela 8).

Das 7.650 formações dos indivíduos, somente 16,65\% (1.274 observações) são de nível de doutorado, enquanto 4,54\% (351 casos) são de pós-doutorado, que representa um nível de conhecimento especializado em termos de pesquisa acadêmica, ainda pouco observado no país. Esta situação também contribui para a estruturação do subcampo acadêmico do turismo quanto a disposição dos agentes, seus interesses e os constrangimentos que motivam seus posicionamentos sociais. 
Tabela 8. Formação em turismo, segundo níveis $(\mathrm{N}=7.650)$

\begin{tabular}{llllll} 
& & \multicolumn{4}{c}{ Formação em turismo } \\
\cline { 3 - 5 } Nivel de formação & n_tur* & tur** & NA & Total \\
& Especialização & 1.254 & 313 & 5 & 1.572 \\
& Doutorado & 1.175 & 99 & 0 & 1.274 \\
& Técnico & 62 & 38 & 215 & 315 \\
& Grado & 1.667 & 681 & 9 & 2.357 \\
& Mestrado & 1.472 & 309 & 0 & 1.781 \\
Total & Pós-doutorado & 0 & 0 & 351 & 351 \\
\hline
\end{tabular}

Nota: *n_tur: formação em outras áreas; **tur: formação específica em turismo.

Fonte: elaborado a partir dos dados da pesquisa.

\subsection{Discussão dos Resultados sobre a Institucionalização das EFIT no Brasil}

A partir dos dados analisados foi possível identificar 3 etapas que marcam o processo de institucionalização das estruturas formais de investigação em turismo/EFIT especializados no tema do turismo no Brasil habitualização, objetivação e sedimentação - segundo o institucionalismo sociológico de Berger e Luckmann (1966; 2004).

Inicialmente observou-se a criação de linhas de pesquisa de turismo, a partir de 1964. Nesta década começava a manifestar-se no país uma nova realidade. Em 1961, criou-se a Divisão de Turismo e Certames no Ministério da Indústria e do Comércio, para examinar e lançar-se ao desenvolvimento do turismo interno. Em 1966 propôs-se a primeira Política Nacional de Turismo, e foi criado o Conselho Nacional de Turismo. Diante destas mudanças o ambiente político-institucional apresenta um cenário favorável para o início da profissionalização do turismo no país.

Das mudanças institucionais elencadas, resultantes de uma alteração na importância atribuída ao turismo no âmbito político marcou-se o inicio de um período de surgimento da educação em turismo no país. Desde modo nesta primeira fase, entre de 1964 e 2001, observa-se uma etapa de Habitualização, com a demanda pela criação de cursos superiores para a formação de profissionais que atuam nesta atividade. A expansão do tema "turismo" no ambiente acadêmico, levou a sua inserção como linha de pesquisa nas estruturas existentes, ou que foram surgindo durante este período, sendo que as primeiras totalmente dedicadas ao estudo deste tema ocorrem na década de 1990.

A segunda fase, da Objetivação, é assinalada no período de 2002 a 2009, pela consolidação do tema turismo via criação de grupos específicos de pesquisa, em grande quantidade, diferentemente dos anos anteriores. Vale ressaltar que, nesta década houve um processo de expansão do ensino técnico e superior, tendo sido refletido na criação de cursos de técnicos e de graduação em turismo no país. Neste contexto a partir de 2005, quando um grande contingente de recém-formados nas carreiras relacionadas com o turismo, e estes indivíduos se inserem no ambiente acadêmico, como professores ou alunos de pósgraduação strictu sensu, observa-se também um aumento significativo da criação de EFIT e na diversificação dos temas estudados por estas estruturas. Assim o turismo começa a especializar-se no país (Trigo, 2003).

Finalmente, a partir de 2010 até o período atual, observa-se um período de Sedimentação das EFIT. Neste momento observa-se o contingente de egressos de graduações em turismo, já com mestrado e doutorado, e inseridos em IES como professores-pesquisadores, começam a formar as novas gerações. Nesta etapa atual já se observam grupos consolidados e que são referência no subcampo acadêmico do turismo. Este é o caso das estruturas vinculadas as IES que tem oferta de pós-graduação em turismo, nas regiões sudeste, nordeste e sul, as quais estão vinculados os pesquisadores de maior reconhecimento na área, em termos de citações bibliográficas. Assim, as ideias produzidas em um cenário específico são reproduzidas em todo o campo do turismo nacional. Esse conhecimento institucionalizado funciona como um determinante social, pois com o tempo se fortalece a ideia de que a pesquisa vinculada a tais IES aonde se produz o conhecimento do campo é central no pensamento e reflexão acadêmica sobre o turismo.

A partir desta descrição se evidencia que o processo de institucionalização da pesquisa formal em turismo no país segue uma trajetória dependente de prioridades da etapa de habitualização, quando ocorre a 
inserção do turismo no ambiente universitário, em que a formação vocacional era prioridade, bem como a concentração de EFIT em instituições de ensino, em termos de acesso, quantidade e qualidade na região sudeste, e na região sul em menor frequência.

Por outro lado, as ações realizadas pelo governo federal para a expansão do ensino universitário no Brasil podem ser consideradas um elemento externo de grande influência na composição do atual sistema de pesquisa em turismo. 0 estimulo à inserção de um grande número de alunos nas IES, e a demanda por novos docentes neste processo, levou a formação de novos professores-pesquisadores que passaram a atuar em grupos de pesquisa, bem como criaram novas EFIT. Isto levou a uma reconfiguração do sistema, que estava em sua fase de objetivação. Assim, a partir de 2006 se observa o aumento da criação de EFIT na região nordeste, com uma rápida expansão, aliado a um processo similar, ainda que em menor escala, nas regiões sul e centro-oeste, o que contribuiu para o alcance a atual fase de sedimentação das EFIT. Nesse sentido, apesar de um centro de produção e reprodução do conhecimento concentrado em um número reduzido de EFIT (as pioneiras na criação de cursos superiores em turismo), que mantem a coerção do pensamento sobre o turismo vinculado as EFIT, começa a esboçar-se um novo cenário, em que pode haver a possibilidade do surgimento de novas interpretações sobre o turismo.

A formação recente de pesquisadores e a alta dispersão em termos das linhas e especialidades temáticas destes indivíduos componentes das EFIT, nos três níveis de formação, também podem ser fator que contribui para a manutenção de uma trajetória temática nas áreas administrativas e de gestão em termos quantitativos e territoriais.

\section{CONCLUSÕES}

A pergunta se o turismo pode ser considerado um campo de conhecimento institucionalizado no Brasil, levantada inicialmente, foi componente motivador da presente análise. Para responder a tal questão, analisou-se o processo de institucionalização - habitualização, objetivação e sedimentação das Estruturas Formais de Investigação em Turismo/EFIT no Brasil, por meio da teoria institucional, com corte sociológico (Berger e Luckmann, 1966; 2004).

A partir dos dados das 234 EFITs, existentes entre 1964 e 2016, aqui analisados foi possível identificar e classificar em 3 etapas que marcam o processo de institucionalização das EFIT no Brasil; 1) na primeira fase (1964-2001) de Habitualização, criaram-se cursos superiores para a formação em turismo, expandiu-se o tema "turismo" no ambiente acadêmico e observou-se sua inserção como linha de pesquisa; 2) na segunda fase, da Objetivação (2002-2009), o tema consolidou-se via criação de grupos específicos de pesquisa, em grande quantidade; e 3) na terceira fase (2010-atual), se sedimentam as EFIT, observa-se o contingente de egressos de graduações em turismo, já com mestrado e doutorado, e inseridos em IES como professorespesquisadores, que começam a formar as novas gerações.

Entretanto, quando vistas em detalhe, as EFIT existentes no campo turístico acadêmico brasileiro parecem estar, ainda, em um estágio inicial de justaposição e adequação espontânea ao espaço físico e social em que se situam, sem desenvolvimentos ulteriores. Assim, parecem, de fato, ter completado a fase de habitualização, em que o tema foi percebido como algo importante e levado à agenda político-institucional; e estar em processo de completar a seguinte, de objetivação, via expansão das EFIT por meio do envolvimento de indivíduos que se identificaram com esta atividade, marcando-se pelo menos dois períodos geracionais na pesquisa da área. 0 primeiro em que há poucos indivíduos, com formações mais diversas, porém afins ao turismo, e centralizados territorialmente na região sudeste do país. No segundo período, é marcado pela expansão, de indivíduos inseridos nestes cenários, de temas pesquisados, da criação de estruturas ao longo das cinco regiões do território nacional. Por outro lado, a influência na produção do conhecimento é centrada entre os agentes da primeira geração destas estruturas, que determinam formas de refletir e agir com relação ao turismo no cenário acadêmico nacional. Portanto, uma plena institucionalização parece ainda requerer esforços no sentido de transmissão intergeracional de estruturas objetivas e referências simbólicas de geração de conhecimento no campo turístico no país. 


\section{AGRADECIMENTOS}

Ao Conselho Nacional de Desenvolvimento Científico e Tecnológico / CNPq e à a Pró-Reitoria de Pesquisa da UFJF pela concessão de bolsas de PIBIC e BIC, respectivamente, junto aos projetos ( $n^{\circ} 38856 / P R O P P /$ UFJF) "Institucionalização do Subcampo Acadêmico do Turismo no Brasil: uma análise da dinâmica interna dos centros de pesquisa em turismo e sua contribuição na formulação de políticas públicas", 2017-2018, e sua continuidade (n ${ }^{\circ} 45821 /$ PROPP/ UFJF) "Por uma Sociologia do Conhecimento em Turismo: o processo de institucionalização das Estruturas Formais de Investigação em Turismo (EFIT) no Brasil", 2018-2019, e aos alunos graduação e de pós-graduação que vieram a colaborar na coleta de dados (em particular a Juliana Cristina Simião Barbosa), ou na execução de alguma fase do mesmo; e aos revisores deste periódico que permitiram o amadurecimento deste trabalho em relação à sua versão inicialmente apresentada.

\section{REFERÊNCIAS}

Araújo, N. de F. \& Malheiros, D. (2013). A participação das mulheres na política institucionalizada do Distrito Federal: Um olhar sobre atuações e repercussões no turismo sustentável. Revista Cenário, 1(1), 108-121.

Archer, M. S. (1998). Critical Realism: Essential Readings. London: Routledge.

Aureli, S. \& Del Baldo, M. (2019) Performance measurement in the networked context of convention and visitors bureaus (CVBs). Annals of Tourism Research, 75, 92-105. https://doi.org/10.1016/i.annals.2018.12.004

Bardin, L. (1977). Análise de conteúdo. Lisboa: Edições 70.

Berger, P. \& Luckmann, T. (1966). The Social Construction of Reality. New York: Anchor.

Berger, P. \& Luckmann, T. (2004). A construção social da realidade: tratado de sociologia conhecimento. Petrópolis: Vozes.

Buckley, W. (1971). A Sociologia e a Moderna Teoria dos Sistemas. São Paulo: Editora Cultrix.

Campos, C. J. G. (2004). Método de Análise de Conteúdo: ferramenta para análise de dados qualitativos no campo da saúde. Revista Brasileira de Enfermagem, Brasília (DF), 57(5), 611-614. https://doi.org/10.1590/S0034-71672004000500019

Carrieri, A. de P.; Saraiva, L. A. S. \& Pimentel, T. D. (2008). A Institucionalização da Feira Hippie de Belo Horizonte. Organizações \& Sociedade, 15, 63-79. https://doi.org/10.1590/S1984-92302008000100004

Carvalho, F. C. C. de (2015). Agenda Governamental e Trajetória Institucional do Turismo no Brasil. Anais Brasileiros de Estudos Turísticos, 5(1), 59-70.

Cintra, R. F.; Amâncio-Vieira, S. F. \& Costa, B. K. (2016). Stakeholder theory e institucionalismo sociológico: complementações para análise do Turismo local. Revista Iberoamericana de Turismo, 6(1), 165-186.

Collier, D.; \& Collier, R. (1991). Shaping the Political Arena. Princeton University Press.

DiMaggio, P. J. \& Powell, W.W. (2005). A gaiola de ferro revisitada: isomorfismo institucional e racionalidade coletiva nos campos organizacionais. Revista de Administração de Empresas, 45(2), 74-89.

DiMaggio, P. \& Powell, W.W. (1991). The New Institutionalism in Organizational Analysis. University of Chicago Press.

Endres, A. V. \& Matias, E. M. (2018). A trajetória das políticas de turismo a partir das perspectivas do institucionalismo histórico: o caso da Paraíba. Revista Iberoamericana de Turismo, 8(1), 221-235.

Estol, J., Camilleri, M. \& Font, X. (June 20, 2018). Tourism Review. Available at SSRN: https://ssrn.com/abstract $=3200033$

Falaster, C.; Zanin, L. M.; \& Guerrazzi, L. A. (2017). Teoria institucional na pesquisa em turismo: novas oportunidades de uma teoria em evolução. Revista Brasileira de Pesquisa em Turismo, 11(2), 270-293. https://doi.org/10.7784/rbtur.v11i2.1310

Fazito, M.; Scott, M. \& Russell, P. (2016). The dynamics of tourism discourses and policy in Brazil. Annals of Tourism Research, 57, 1-17. https://doi.org/10.1016/j.annals.2015.11.013

Friedberg, E. (1996). Organização. En. Boudon, R., \& Baechler, J. Tratado de sociologia. Rio de Janeiro: Jorge Zahar, 375-412. 
Gadamer, H.-G. (1999) Verdade e Método: traços fundamentais de uma hermenêutica filosófica. Petrópolis: Editora Vozes.

García-Cabrera, A. M. \& Durán-Herrera, J. J. (2014) Does the tourism industry co-evolve? Annals of Tourism Research, 47, 81-83. https://doi.org/10.1016/j.annals.2014.05.004

Gil, A. C. (2008). Métodos e técnicas de pesquisa social. São Paulo: Atlas. (Originalmente publicado em 1995)

Gomes, B. M. A.; Vargas-Sánchez, A. \& Pessali, H. F. (2014). Interação Empresários-Setor Público no Turismo: uma análise institucional e neocorporativista na cidade de Huelva (Espanha). Revista Brasileira de Pesquisa em Turismo, 8(3), 382-402. https://doi.org/10.7784/rbtur.v8i3.760

Goodin, R. E.; Rein, M.; \& Moran, M. (2008) The Public and its Policies. In: Moran, M.; Rein, M.; Goodin, R. E. The Oxford Handbook of Public Policy. p. 3-35. Oxford University Press. https://doi.org/10.1093/oxfordhb/9780199548453.003.0001

Gouveritch, P. (1986). Politics in Hard Times: comparative responses to international economic crises. Ithaca and London: Cornell University Press.

Gyr, U. (2010). The History of Tourism: Structures on the Path to Modernity, In: European History Online (EGO). Published by the Institute of European History (IEG), Mainz 2010-12-03. Available at: http://www.iegego.eu/gyru-2010-en. Retrieved in: 20/01/2019.

Hall, P. \& Soskice, D. (2001) Varieties of Capitalism: the institutional foundations of comparative advantage. Oxford: Oxford University Press.

Hall, P. (1986) Governing the Economy: The Politics of State Intervention in Britain and France. Cambridge: Polity Press.

Hall, P. A.; \& Taylor, R. C. A. (2003). As três versões do neo-institucionalismo. Lua Nova: Revista de Cultura e Política, 58, 193-223. http://dx.doi.org/10.1590/S0102-64452003000100010.

Immergut, E. M. (2007). O Núcleo teórico do Novo Institucionalismo. En: Saravia, E. \& Ferrarezi, E. Políticas Públicas. Coletânia, v. 1. Brasília: ENAP.

Lasswell, H. D. (1927). Propaganda Techinique in the World War (1 $1^{\mathrm{a}}$ Ed.). University of Michigan.

Lavandoski, J.; Albino Silva, J.; \& Vargas-Sánchez, A. (2014). Institutional Theory in Tourism Studies: Evidence and Future Directions. Spatial and Organizational Dynamics Discussion Papers, 2014-3, CIEO-Research Centre for Spatial and Organizational Dynamics, University of Algarve.

Le, Y.; Hollenhorst, S.; Harris, C.; McLaughlin, W. \& Shook, S. (2006). Environmental management: A Study of Vietnamese Hotels. Annals of Tourism Research, 33(2), 545-567. https://doi.org/10.1016/j.annals.2006.01.002

Mahoney, J. (2000) Path dependence in historical sociology. Theory and Society, 29(4), 507-548.

Mahoney, J.; \& Schensul, D. (2006). Historical Context and Path Dependence. In: Goodin. R. \& Tilly, C. The Oxford Handbook of Context Political Analysis. The Oxford Handbooks of Political Science. Oxford: Oxford University Press. 454-471. https://doi.org/10.1093/oxfordhb/9780199270439.003.0024

March, J., \& Olsen, J. P. (1984). The New Institutionalism. Organizational Factors in Political Life. American Political Science Review, 78, 734-749. https://doi.org/10.2307/1961840

March, J.G.; Olsen, J.P. (2008) Neo-Institucionalismo: Fatores Organizacionais na Vida Política. Revista Sociologia Política, Curitiba, 16(31), 121-142. http://dx.doi.org/10.1590/S0104-44782008000200010

Merton, R. (1945) Sociology of Knowledge. (Chapter XIII: pp. 366-405). In: Gurvitch, G. \& Moore, W. (Ed.) Twentieth Century Sociology. New York: The Philosophical Library.

Meyer, J. W. \& Scott, W. R. (1983). Organizational Environments. Ritual and Rationality. Beverly Hills, Sage.

Meyer, W.; \& Rowan, B. (1977). Institutionalized Organizations. Formal Structure as Myth and Ceremony. American Journal of Sociology, 83, 340-363. https://doi.org/10.1086/226550

Moraes, R. (1999). Análise de Conteúdo. Revista de Educação, Porto Alegre, 22(37), 7-32.

Mozzato, A. R. \& Grzybovksi, D. (2011). Análise de Conteúdo como Técnica de Análise de Dados Quantitativos no Campo da Administraçnao: potencial e desafios. Revista de Administração Contemporânea - RAC. Curitiba, 15(4), 731-747. https://doi.org/10.1590/S1415-65552011000400010 
Musselin, C. (2005). Sociologie de l'action organisée et analyse des politiques publiques: deux approches pour un même objet? Revue Française de Science Politique, 55(1), 51-71. https://doi.org/10.3917/rfsp.551.0051

Nunkoo, R.; Ramkissoon, H. \& Gurso, D. (2012). Public trust in tourism institutions. Annals of Tourism Research, 39(3), 1538-1564. https://doi.org/10.1016/j.annals.2012.04.004

Peters, B. G. (2000). Institutional Theory: Problems and Prospects. Reihe Politikwissenschaft/Political Science Series 69. Institute for Advanced Studies, Vienna, 1-20.

Peters, B. G. (1999). El nuevo Institucionalismo. Teoría Institucional en Ciencia Política. Barcelona: Editorial Gedisa S.A.

Pierson, P. (2003). Slow moving and invisible: macrosocial process in the study of comparative politics. In Mahoney, J. \& Rueschemeyer, D. (org.) Comparative Historical Analysis in the Social Sciences. Cambridge University Press.

Pimentel, M. P. C. (2014). Uma Discussão Teórico-Metodológica para a Análise das Políticas de Turismo no Brasil. In: Pimentel, T. D.; Emmendoerfer, M. L. \& Tomazzoni, E. L. Gestão Pública do Turismo no Brasil: teorias, metodologias e aplicações. Caxias do Sul, RS; EDUCS, 2014. (Capítulo 12, pp.317-331).

Pimentel, T. D. (2014a) Realismo crítico nos estudos organizacionais: notas introdutórias sobre seus fundamentos filosóficos. Farol-Revista de Estudos Organizacionais e Sociedade, 1(2), 609-656.

Pimentel, T.D. (2014b) Bourdieu, Campo Turístico y sus Implicaciones para la Gobernanza de los Destinos Turísticos. ARENAS - Revista Sinaloense de Ciencias Sociales, (35), 118-125.

Pimentel, M. P. C.; Pereira, J. R. \& Boas, A. A. V. (2011). A Institucionalização das políticas públicas de turismo em âmbito municipal no Brasil. En. Pereira, J. R. (Org.). Gestão Social de Políticas Públicas. Lavras: UFLA.

Pimentel, T. D. (2016a). Mapeamento dos Centros de Pesquisa e da Oferta Educacional de Cursos de Turismo no Brasil e no Exterior: notas preliminares para delimitação do campo turístico mundial. Relatório de Pesquisa. Conselho Nacional de Desenvolvimento Científico e Tecnológico/CNPq e Pró-reitoria de Pesquisa da Universidade Federal de Juiz de Fora/PROPESQ-UFJF, Minas Gerais (MG), Brasil.

Pimentel, T. D. (2016b). Distribución de la Oferta Educativa (OET) y de las Estructuras Formales de Investigación en Turismo (EFIT) en México. Revista Latino Americana de Turismologia, 2, 25-48.

Pimentel, T. D., Carvalho, F. C. C. de \& Bifano-Oliveira, M. (2017). Distribución de la oferta educativa (OET) y de las estructuras formales de investigación en turismo (EFIT) en Ecuador. Turismo y Sociedad, XXI, 193215. https://doi.org/10.18601/01207555.n21.09

Pimentel, T. D.; Carvalho, F. C. C. \& Oliveira, M. C. B. (2018). Centros de Pesquisa em Turismo no Mercosul: distribuição, ênfases e possíveis interações como fator de desenvolvimento. Revista Gestão Universitária da América Latina, 11, 321-344. https://doi.org/10.5007/1983-4535.2018v11n1p321

Pimentel, T. D.; Carvalho, F. C. C. \& Pimentel, M. P. C. (2017). Mapeamento da Oferta Educacional e das Estruturas Formais de Pesquisa em Turismo no Brasil. Journal of Tourism and Development, 27/28, 1771 1784.

Pimentel, T. D. \& Paula, S. C. (2014). Desenvolvimento de um protocolo de avaliação do desempenho de recursos humanos em instituições de ensino superior/IES: notas para a gestão acadêmica a partir do caso do Curso de Turismo/UFJF - Brasil. Revista Gestão Universitária na América Latina - GUAL, 7, p. 243-265. https://doi.org/10.5007/1983-4535.2014v7n2p243

Scott, J. (1995). Sociological Theory: Contemporary Debates. Aldershot, Edward Elgar Publishing.

Silva, A. H. \& Fossá, M I. T. (2015). Análise de Conteúdo: exemplo e aplicação da técnica para análise de dados qualitativos. Qualit@s Revsta Eletrônica, 17(1), 1-14. https://doi.org/10.18391/req.v17i1.2963

Silva, C. G. da. (2017). Impactos de programas nacionais de turismo sobre as instituições e organizações turísticas nos municípios do Pará (Brasil). Turismo e Sociedade, 10(3), 1-19. http://dx.doi.org/10.5380/tes.v10i3.53499

Skocpol, T. (1979) States and Social Revolutions. Cambridge University Press. https://doi.org/10.1017/CB09780511815805

Song, H.; Dwyer, L.; Li. G. \& Cao, Z. (2012). Tourism economics research: A review and assessment. Annals of Tourism Research, 39(3), 1653-1682. https://doi.org/10.1016/j.annals.2012.05.023 
Thelen, K. (2004). How Institutions Evolve: The Political Economy of Skills in Germany, Britain, the United States, and Japan. Cambridge: Cambridge University Press. https://doi.org/10.1017/CB09780511790997

Tolbert, P. S. \& Zucker, L. G. (1998). A institucionalização da teoria institucional. In. Clegg, S., Hardy, C.; \& Nord, W. (Org.). Handbook de estudos organizacionais. São Paulo: Atlas.

Trigo, L. G. G. (2003). Turismo. Como aprender, como ensinar. São Paulo: SENAC.

Triviños, A.R.S. (1987) Introdução à pesquisa em ciências sociais: Pesquisa Qualitativa em Educação. São Paulo: Atlas.

Wilke, E. P. \& Rodrigues, L. C. (2013). Fontes de pressão institucional: reflexões sobre legitimidade na indústria hoteleira brasileira. Revista Brasileira de Pesquisa em Turismo, 7(2), 337-357. https://doi.org/10.7784/rbtur.v7i2.645

Zucker, L. (1987). Institutional Theories of Organizations. Annual Review of Sociology, 13, 443-464. https://doi.org/10.1146/annurev.so.13.080187.002303

\section{Informações dos autores}

\section{Thiago Duarte Pimentel}

Doutor em Ciências Sociais pela Universidade Federal de Juiz de Fora (UFJF). Mestre em Administração pela Universidade Federal de Minas Gerais (UFMG). Bacharel em Turismo/UFMG. Professor e pesquisador de dedicação exclusiva na UFJF, na pós-graduação em Ciências Sociais (M/D) e em Administração (M), e também nos cursos de bacharelado em Ciências Humanas e de Turismo. Membro da Associação Internacional de Sociologia (ISA) e da Associação Internacional de Peritos Científicos em Turismo (AIEST). Professor visitante nos EUA, Canadá, México, Cuba, Equador. Líder da rede de pesquisa: Realismo Crítico, Ação Coletiva e Trabalho (REACT). Diretor do Centro de Excelência Latino Americano em Turismologia (CELAT) e do Observatório Económico e Social do Turismo (OEST). Editor Chefe das Revistas Anais Brasileiros de Estudos Turísticos (ABET) e Revista Latino Americana de Turismologia (RELAT).

Contribuição do autor: concepção da pesquisa; revisão da literatura; coleta de dados; análise de dados; discussão.

E-mail: thiago.pimentel@ich.ufjf.br

ORCID: https://orcid.org/0000-0003-1889-069x

\section{Fabíola Cristina Costa de Carvalho}

Pós-doutoranda na Universidade de Guadalajara - Centro Universitario de la Costa. Doutora em Ciências Sociais. Mestre em Administração Pública. Bacharel em Turismo. Integrante Centro de Excelência Latino Americano em Turismologia/CELAT e Observatório Econômico e Social do Turismo/OEST, vinculados a Universidade Federal de Juiz de Fora/Brasil. Interessa-se e atua nas áreas de Turismo, Ciências Sociais, Ciência Política e Administração Pública, com ênfase, nas seguintes linhas de pesquisa e campos temáticos: (1) Turismo: História e Modelos Explicativos do Turismo, Gestão e Planejamento do Destino Turístico, Elementos Intervenientes no Sistema Turístico, Educação em Turismo, Epistemologia do Turismo; (2) Ciências Sociais: Epistemologia, Teoria Social, Realismo Crítico; (3) Teoria Política: Instituições e Políticas Públicas; (4) Administração Pública: Gestão Pública, Paradigmas da Gestão Pública, Participação Social.

Contribuição da autora: revisão da literatura; coleta de dados; análise de dados; discussão.

E-mail: fabiolacarvalho.tur@hotmail.com

ORCID: https://orcid.org/0000-0001-5719-9020

\section{Mariana Pereira Chaves Pimentel}

Doutora em Ciências Sociais pela Universidade Federal de Juiz de Fora (UFJF). Mestra em Administração pela Universidade Federal de Lavras (UFLA). Bacharela em Turismo/UFMG. Professora e pesquisadora de dedicação exclusiva na UFJF, nos cursos de bacharelado em Ciências Humanas e de Turismo. Membro da rede de pesquisa: Realismo Crítico, Ação Coletiva e Trabalho (REACT). Vice-Diretora do Observatório Económico e Social do Turismo (OEST).

Contribuição da autora: revisão da literatura; análise de dados; discussão.

E-mail: marianachaves82@yahoo.com.br

ORCID: https://orcid.org/0000-0003-0624-6127 